\title{
Thermally Induced Fullerene Domain Coarsening Process in Organic Solar Cells
}

\author{
Antonio Agresti ${ }^{\circledR}$, Sara Pescetelli, Yan Busby, and Tom Aernouts
}

\begin{abstract}
The recent advancements in power conversion efficiency for organic solar cells is still complained by their reliability and stability remaining the main bottlenecks for organic photovoltaics large scale production and commercialization. In this paper, we aim to provide further insights understanding in degradation processes affecting stability in small molecule flat heterojunction (Glass/ITO/MoO $/ \mathrm{ZnPc}_{3} / \mathrm{C}_{60} / \mathrm{BCP} / \mathrm{Ag}$ ) solar cells through a systematic aging study coupled with optoelectrical characterizations. In particular, the burn-in phenomenon affecting short-circuit current in thermal-stressed samples has been clearly correlated with the $\mathrm{C}_{60}$ domain coarsening process and eventually to the decreased exciton lifetime.
\end{abstract}

Index Terms-Burn-in effect, degradation mechanisms, organic solar cells (OSCs) stability, spectroelectrochemical characterization techniques.

\section{INTRODUCTION}

$\mathbf{O}$ RGANIC solar cells (OSCs) have attracted great attention in the past two decades because of their flexible, lightweight, and low-cost technology [1]-[3]. They can be fabricated from various organic compounds with modifiable structures and exhibit excellent flexibility and high power conversion efficiency (PCE) under low-light irradiation [4], [5]. As matter of fact, the commercialization of these technologies requires an integrated overview that comprises efficiency, stability, costs, and environmental impact.

Regarding OSCs, several materials and numerous structures were proposed in the literature focusing on device efficiency and/or stability [6]. Different polymers and small

Manuscript received August 17, 2018; revised October 22, 2018; accepted November 2, 2018. This work was supported by the European Union's Horizon 2020 Research and Innovation ProgrammeGrapheneCore2 under Grant 785219. The review of this paper was arranged by Editor A. G. Aberle. (Corresponding author: Antonio Agresti.)

A. Agresti is with the Electrical Engineering Department, University of Rome Tor Vergata, 00133 Rome, Italy, and also with the Thin-Film Photovoltaics Group, PV Department, imec, 3001 Leuven, Belgium (e-mail: antonio.agresti@uniroma2.it).

S. Pescetelli is with the Electrical Engineering Department, University of Rome Tor Vergata, 00133 Rome, Italy.

Y. Busby is with the Laboratoire Interdisciplinaire de Spectroscopie Electronique, Namur Institute of Structured Matter, University of Namur, 5000 Namur, Belgium.

T. Aernouts is with the Thin-Film Photovoltaics Group, PV Department, imec, 3001 Leuven, Belgium.

Color versions of one or more of the figures in this paper are available online at http://ieeexplore.ieee.org.

Digital Object Identifier 10.1109/TED.2018.2880760 molecules can be arranged in a tandem configuration to achieve record PCE. In particular, Meng et al. [7] recently demonstrated polymer-based tandem solar cells with $17.3 \%$ efficiency, while Heliatek $\mathrm{GmbH}$ announced a record-breaking $12.0 \%$ cell efficiency for a tandem structure realized by employing the high-vacuum deposition technique (https://www.nrel.gov/pv/assets/images/efficiency-chart20180716.jpg). Such technique ensures high purity of the deposited film and a controllable deposition of multilayer structures by consecutive evaporations. Furthermore, beside vacuum processing is supposed to be more cost intensive considering initial investments, these costs would be amortized by a high-throughput production, by the low costs of the required raw materials and by an easy and eco-friendly disposal of the expired devices. Despite the certified efficiencies for OSC underwent a remarkable improvement and are now in line with the other emerging photovoltaic (PV) technologies (https://www.nrel.gov/pv/assets/images/efficiency-chart20180716.jpg), the long-term stability is still tightly related to the material used for the device layers, to the deposition procedures and to the encapsulation techniques. Thus, the OSCs stability issue should be addressed by taking into account either the typical degradation mechanisms under real working conditions or the testing protocols for organic PV devices established in 2011 within the international summit on organic PVs stability (ISOS) [8].

In particular, Reese et al. [8] agreed on some different test protocol categories listed as dark, outdoor, simulated light and stress testing, and thermal cycling with the aim to increase the amount of data that can readily be compared between different laboratories. Furthermore, the deeply increasing understanding on degradation mechanisms could push the OSC technology toward the market production.

The degradation of OSCs can be divided into intrinsic and extrinsic processes. The first is caused by the thermal interdiffusion of constituent species inside OSCs, while the latter is caused by the intrusion of air and moisture. Recently, Cao et al. [9] reviewed the main extrinsic degradation processes at the organic material/aluminum cathode interface, in a copper-phthalocyanine/fullerene $\left(\mathrm{CuPc} / \mathrm{C}_{60}\right)$ heterojunction, in the case of light stress and oxygen or water. The contact between oxygen and the active layer can occur during the fabrication process, when the device is transferred after the evaporation of organic substances in a dedicated metal 
evaporator, during the encapsulation process whether it is done in air, or after the realization of the device when it is kept in air or in controlled humidity conditions.

Furthermore, the ambient humidity has been suggested to play an important role in the degradation of OSCs, particularly when hydrophilic materials such as poly(3, 4-ethylenedioxythiophene) polystyrene sulfonate (PEDOT:PSS) [10] is used as hole transporting layer (HTL), or bathocuproine (BCP) and bathophenanthroline (BPhen) [11] are used as an electron blocking layer (EBL) in the presence of aluminum cathode. In fact, the physical swelling or recrystallization of these materials as well as the corrosion of active cathodes in the presence of these hygroscopic materials accelerate the device degradation by forming insulating interfaces or interfacial voids. In order to investigate the OSCs intrinsic degradation mechanisms affecting the active layer materials, the EBL/cathode, as well as the HTL/anode degradations, should be avoided. In this regard, Sun et al. [12] demonstrated that OSCs employing molybdenum oxide $\left(\mathrm{MoO}_{\mathrm{x}}\right)$ as HTL are more stable than those employing PEDOT:PSS while very recently Chalal et al. [13] employed a silver cathode covering the whole device's active area to enlarge the cell lifetime under standard illumination and at ambient atmosphere.

Furthermore, despite the considerable understanding of water and oxygen aging effects on the stability of small molecule PV devices [11], [14]-[16], few studies attempted to investigate the effect of temperature stress by clearly separating the moisture contribution to the degradation mechanisms.

In this studies, glass-glass encapsulated planar heterojunction small molecule solar cells with the following structure ITO-glass/molybdenum trioxide $\left(\mathrm{MoO}_{3}\right) /$ zinc-phthalocyanine $(\mathrm{ZnPc}) / \mathrm{C}_{60} / \mathrm{BCP} /$ silver $(\mathrm{Ag})$ underwent a thermal aging test in line with the protocol established in [8] by carefully identifying the contributions of each degrading agent to the overall device performance degradation. The presence of $\mathrm{MoO}_{3}$ as HTL and of Ag cathode ensures stable HTL/anode and EBL/cathode interfaces, respectively, while the planar heterojunction tested in this paper showed and average PCE of 1.5\%, in line with the values reported in the literature [17]-[19]. The simple device structure allowed to carefully detect the degradations underwent by the donor $(\mathrm{ZnPc})$ and acceptor $\left(\mathrm{C}_{60}\right)$ active layers. In particular, this paper gives clear evidence of a coarsening phenomenon affecting the $\mathrm{C}_{60}$ grains when the device undergoes a prolonged thermal stress (at $85^{\circ} \mathrm{C}$ ) in the inert atmosphere. Consequently, the usually observed burn-in phenomenon, consisting in a degradation of the device electrical parameters before to reach a stabilized value is finally unequivocally explaining in term of decreased excitons lifetime.

\section{EXPERIMENTAL DETAIL}

\section{A. OSC Realization and Encapsulation}

ITO patterned glass substrates $\left(3 \times 3 \mathrm{~cm}^{2}\right)$ (sheet resistance between 8 and $10 \Omega / \square$ ) and glass lid for the final encapsulation were solvent cleaned by ultrasonication bath at $60^{\circ} \mathrm{C}$ for $5 \mathrm{~min}$ in deionized water with soap, acetone, and 2-propanol. The described cleaning procedure was repeated twice before the drying step with a nitrogen flow. After cleaning, the substrate was loaded in a glove box (GB) system comprising two high-vacuum evaporators for metallic and organic substances, respectively. All the thin films were deposited by thermal evaporation in high vacuum $\left(<10^{-7} \mathrm{mBar}\right)$ with the deposition rates monitored in situ with quartz crystal microbalances and controlled between 0.5 and $1 \AA /$ sec. 12 device areas of $0.13 \mathrm{~cm}^{2}$ cells were realized on the same substrate by the intersection of the prepatterned ITO anode and the Ag cathode. The as-realized complete solar cell was a planar heterojunction with the following structure ITO-Glass $/ \mathrm{MoO}_{3}(5 \mathrm{~nm}) / \mathrm{ZnPc}$ $(40 \mathrm{~nm}) / \mathrm{C}_{60}(50 \mathrm{~nm}) / \mathrm{BCP}(10 \mathrm{~nm}) / \mathrm{Ag}(120 \mathrm{~nm})$; each substrate (six in total) was glass-glass encapsulated in an inert atmosphere with an automatized encapsulation setup developed by M-Brawn (MB-UV-Press). All the samples were encapsulated at the same time since the MB system allows loading up to nine substrates. In particular, after the devices realization, the substrates were transferred into the MB encapsulation box together with the glass lid by prior dispensing a UV-curable glue (DELO 655) onto the glass lids edge. The encapsulation process comprising the glue UV curing step was carried out in low-vacuum condition (600 mBar) in order to avoid nitrogen intrusion in the glue edge by enormously enlarging the encapsulation lifetime. At this purpose, electrical calcium test was used to estimate an encapsulation lifetime of $150 \mathrm{~h}$ under harsh stress condition $\left(85^{\circ} \mathrm{C}\right.$ and $85 \%$ of humidity rate). The entire devices realization process from the layer deposition to the encapsulation was carried out in an inert atmosphere (purified $\mathrm{N}_{2} \mathrm{~GB}, \mathrm{H}_{2} \mathrm{O}<1 \mathrm{ppm}, \mathrm{O}_{2}<1 \mathrm{ppm}$ ) by never exposing the film to air or moisture contact.

\section{B. Stress Tests}

The applied stress tests were carried out by leaving the samples in dark and in open-circuit condition. The performed stress tests are detailed as follows: 1) the sample A was stored in inert ambient conditions (GB) at room temperature (RT) likewise the shelf life test proposed by ISOS-D-1 (shelf) but avoiding the atmosphere contaminations and 2) the sample B was stored in inert atmosphere by fixing the aging temperature at $85{ }^{\circ} \mathrm{C}$ as proposed by the standard ISOS-D-2 (high-temperature storage) but avoiding the atmosphere contamination [8]. The choice to perform standard stress test 1) and 2) in the inert environment instead of in atmosphere condition (as suggested by the standard ISOS procedure) aims to separate carefully the different degrading agent's effects on the devices performance by accurately pointing out the main degradation mechanisms.

\section{Electrical Measurements and Spectroscopic Characterization}

PV characteristics were measured at regular intervals in ambient atmosphere with a Keithley 2602A in the four-wire configuration under a Lot Oriel 1000W Xenon arc lamp filtered by OD0.8 Newport neutral density to obtain $100-\mathrm{mW} / \mathrm{cm}^{2}$ illumination intensity and AM1.5G spectrum. The lamps intensity was calibrated with an integral of squared error Fraunhofer certified Si photodiode. Characterization of 
one substrate (12 devices) requires a total illumination of $40 \mathrm{~s}$ resulting in a cumulated illumination of 5-10 min over the aging study.

Transient measurements [open-circuit photovoltage decay (OCVD)] were performed with a customized PXI (National Instruments)-based platform (Arkeo) detailed in [20]-[22]. Equivalent incident power of $1 \mathrm{SUN}\left(100 \mathrm{~mW} \mathrm{~cm}{ }^{-2}\right)$ was calibrated through the mismatch factor with a certified reference Si cell (RERA Solutions RR-1002).

Incident photon-to-current conversion efficiency (IPCE) spectra were collected by means of an inverted microscope (Leica DMI 5000) coupled with a monochromator (Cornerstone 130) illuminated by a $200-\mathrm{W}$ Xenon Lamp. The excitation wavelength resolution was $\pm 2 \mathrm{~nm}$. A long working distance objective with $100 \times$ of magnification yielded a $50 \times 50 \mu \mathrm{m}$ of spot area. A calibrated silicon photodiode was coupled with a beam splitter at the optical entrance of the microscope in order to monitor the incident optical power. The short-circuit photocurrents of both the devices and the calibrated photodiode were discriminated by a phase sensitive detection system composed by an optical chopper $(177 \mathrm{~Hz}$ of modulation) and two digital lock-in amplifiers (Eg\&g 7265). A detailed description of the setup can be found in [23] and [24].

Electroluminescence (EL) spectra were acquired by using a spectrograph Acton SpectraPro (SP2300i) from Princeton Instrument equipped with a silicon charge-coupled device array detector (Pixis 400) [25]. The injection current used was $10 \mathrm{~mA}$ while the wavelength resolution was $2 \mathrm{~nm}$ by considering a grating of 1200 lines $/ \mathrm{mm}$.

$\mathrm{UV}-\mathrm{V}$ is absorption spectra were recorded using $\mathrm{UV}-\mathrm{V}$ is 2550 spectrophotometer from Shimadzu. A detailed description of the setup can be found in [26]-[28]. The spectra were collected over a scan range from 300 to $800 \mathrm{~nm}$ by employing a scan rate of $480 \mathrm{~nm} / \mathrm{min}$ with a resolution of $1 \mathrm{~nm}$.

Micro Raman spectra were acquired on a Jobin-YvonHoriba system (LabRAM ARAMIS) in a backscattering geometry (see details in [26], [27], and [29]). The laser light reached the sample surface at normal incidence by ultralong working distance $(50 \times)$ objective with $10.5-\mathrm{mm}$ focal distance and with a laser power density (after filtering) of about $0.026 \mathrm{~mW} / \mu \mathrm{m}^{2}$. Subtraction of the fluorescence background on the Raman spectra was performed by using polynomial fitting, while spectral deconvolution was carried out by nonlinear least squares fitting of the Raman peaks to a mixture of Lorentzian and Gaussian line shapes by providing the peak position.

Time-of-flight secondary ion mass spectrometry (ToFSIMS) 3-D imaging (TOF-SIMS IV from Ion-TOF GmbH, Münster, Germany) was performed with a dual-beam spectrometer equipped with a $25-\mathrm{keV} \mathrm{Bi}_{3}^{+}$beam for the analysis and a $500-\mathrm{eV} \mathrm{Cs}^{+}$ion beam for the sputtering (sputtering operated in the noninterlaced bunched mode) [30].

\section{Results And Discussion}

\section{A. Steady-State and Transient Electrical Characterization}

Four encapsulated samples (for a total of 48 planar heterojunction solar cells) were realized as described in
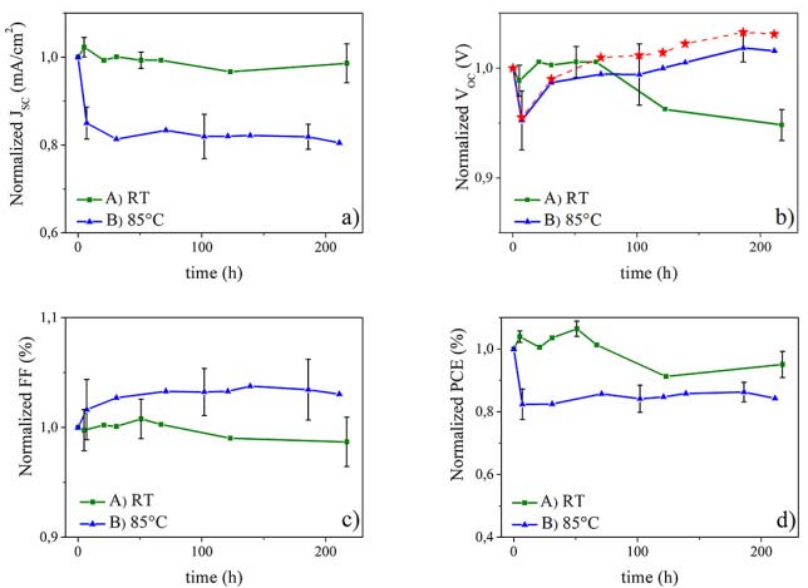

Fig. 1. Time evolution of the devices electrical parameters (a) $J_{S C}$, (b) $V_{\mathrm{OC}}$, (c) FF, and (d) PCE extracted from $I-V$ characteristics under 1 SUN illumination condition. The standard deviation was calculated considering 24 devices for each stress type. In particular, curve $A$ is related to the reference sample $A$, stored in $\mathrm{GB}\left(\mathrm{H}_{2} \mathrm{O}<1 \mathrm{ppm}, \mathrm{O}_{2}<\right.$ $1 \mathrm{ppm}$ ) at RT while curves $\mathrm{B}$ to sample $\mathrm{B}$ stored in $\mathrm{GB}$ at $85^{\circ} \mathrm{C}$. The red star symbols reported in (b) are related to $V_{\mathrm{OC}}$ value calculated by employing (1) and by considering the real recorded values for $n, J_{0}$, and $J_{S C}$ acquired during the stress test.

Section II. The electrical performance was extracted by the current-voltage $(I-V)$ measurements performed at 1 SUN illumination condition and RT in GB environment by showing the following averaged values: open-circuit voltage $\left(V_{\mathrm{OC}}\right)=$ $0.5 \mathrm{~V}$, short circuit density of current $\left(J_{\mathrm{SC}}\right)=5.8 \mathrm{~mA} / \mathrm{cm}^{2}$, fill factor $(\mathrm{FF})=54 \%$, and $\mathrm{PCE}=1.5 \%$. After the preliminary $I-V$ characterization, two samples were stored in GB in dark at RT (sample A) while the remaining two samples were stored in GB over a hot plate at $85{ }^{\circ} \mathrm{C}$ in the dark (sample B), as detailed in Section II. The ongoing stress test effects onto the device PV performance were monitored by acquiring the $I-V$ characteristics in GB at different stress stages over an overall aging period of about $200 \mathrm{~h}$. The time evolution of each PV parameter extracted from $I-V$ curves under 1 SUN illumination is reported in Fig. 1. Each averaged value (24 devices for each stress test) is reported together with the standard deviation. Reference sample A exhibited quite flat trends for all the investigated PV parameters till the end of the stress test by demonstrating device's performance unaffected by the storage in $\mathrm{N}_{2}$ environment. On the contrary, temperature dramatically reduced the $J_{\mathrm{SC}}(-20 \%)$ in parallel with an increase in $V_{\mathrm{OC}}$ and FF [Fig. 1(b) and (c)], by leading to an overall decrease in the PCE of about $18 \%$.

Several authors investigated the dependence of the $V_{\mathrm{OC}}, J_{\mathrm{SC}}$, and $\mathrm{FF}$ from the active material properties [31]-[33], charge geminate and nongeminate recombination at donor/acceptor (D/A) interfaces [34], [35], charge recombination during the transport toward the electrodes [36], [37], electrode/organic layer interface recombination [38], defects or vacancies in the active or transporting materials [16]. As our knowledge, all the reported degradation mechanism investigations till now could not unequivocally exclude the presence of water and oxygen trapped in the 
devices during the fabrication and the encapsulation process or the presence of moisture during the characterizations procedure.

From here, the difficulty in investigating the degradation mechanisms affecting the active layers, since organic transport layer materials such as PEDOT:PSS, BCP, and BPhen are enormously affected by water molecules intrusions.

To this end, we decided to exclude unequivocally the contacts and transporting layer degradations induced by oxygen or moisture by carrying out the complete device's realization, the encapsulation, the $I-V$ characterization, and the thermal testing in the inert atmosphere.

As a further control, the glass-glass encapsulation proposed in this paper has been tested in a climate chamber with harsh environmental condition $\left(85^{\circ} \mathrm{C}\right.$ and $85 \%$ relative humidity) by getting an encapsulation lifetime of about $150 \mathrm{~h}$. This allowed to ensure a complete device isolation from the external environment during the complete duration of performed stress tests. Moreover, Ag and ITO have been employed in the device's structure as electrodes while $\mathrm{MoO}_{3}$ and $\mathrm{BCP}$ as transporting layers because of their high stability when not in contact with water and oxygen [16]. In addition, the simple structure of the investigated planar heterojunction allowed focusing the attention on the stress-induced degradation suffered by both active bulk materials and the D/A interfaces.

As a matter of fact, several theoretical [39] and experimental studies [40], [41] demonstrated the crucial influence on the overall device's performance played by the morphology of the active D/A materials and their interfaces. Among them, Vandewal et al. [41] proposed (1) to correlate $V_{\mathrm{OC}}$ with the energy of charge transfer states $\left(E_{\mathrm{CT}}\right)$ and with the dark saturation current of the cell $\left(J_{0}\right)$ as following reported:

$$
V_{\mathrm{oc}}=\frac{E_{\mathrm{CT}}}{q}+n \frac{k T}{q} \ln \left(\frac{J_{\mathrm{sc}}}{J_{0}}\right)
$$

where $n$ is the ideality factor, $T$ is the temperature, $q$ is the elementary charge, and $k$ is Boltzmann's constant.

In fact, when Ohmic contacts are deployed, $V_{\mathrm{OC}}$ has been demonstrated to be related to the recombination dynamics of the free charge carriers [42] and to the energy of the interfacial electron-hole pair or charge transfer state $E_{\mathrm{CT}}$ [43]. In particular, the D/A interfacial area has been demonstrated to strongly affect both the device's $V_{\mathrm{OC}}$ and the dark saturation current $J_{0}$. In fact, the probability that electron and hole meet each other and thus recombine is determined by the interfacial area available, by strongly affecting the recombination dynamic and eventually by limiting the device's $V_{\mathrm{OC}}$. On the other hand, the smaller is the D/A interfacial area, the lower is $J_{0}$ by finally increasing the $V_{\mathrm{OC}}$ [41] in accordance with (1). Moreover, when $\mathrm{C}_{60}$ is used as an acceptor material, a weak intermolecular interaction at $\mathrm{D} / \mathrm{A}$ interface has been demonstrated to result in a reduced $J_{0}$ value [44]. Starting from this assumptions, $J_{0}$ versus aging time $\left[J_{0}(\mathrm{t})\right]$ trends are reported in Fig. 2(a) for Samples A and B; $J_{0}$ values were extracted from the in-dark $I-V$ characteristic acquired in GB at each stress stage before the characterization under 1 SUN irradiation. Note that thermal-stressed sample B showed a clear $J_{0}(\mathrm{t})$ decreasing trend if compared with a more random $J_{0}(\mathrm{t})$
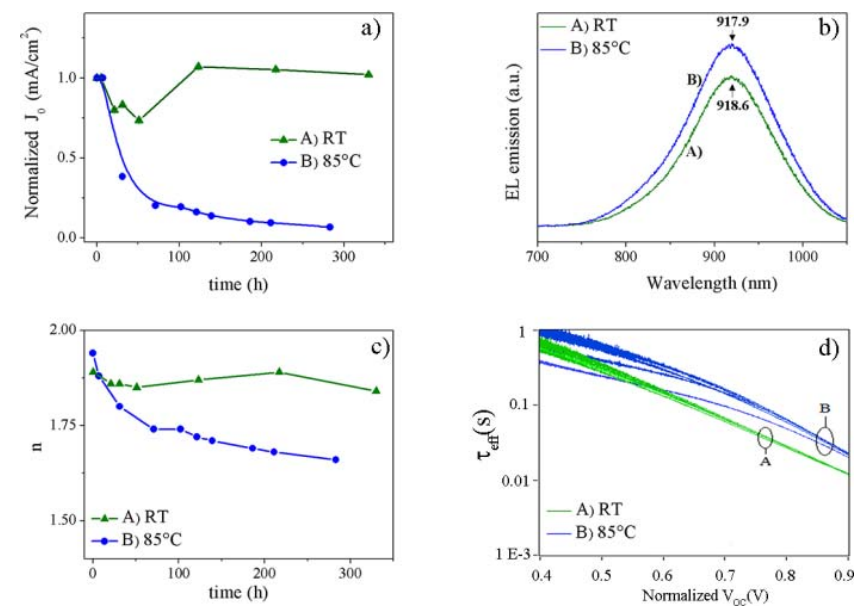

Fig. 2. (a) Dark saturation current $J_{0}(t)$ and (c) ideality diode factor ( $n$ ) trends versus aging time, extracted from the in-dark $l-V$ characteristics of the investigated samples A (curve A) and B (curve B). (b) EL emission spectra; the emission peaks were calculated by employing a nonlinear least-squares fitting with Gaussian line shapes. (d) Charge carrier life time $\tau_{\text {eff }}$ versus normalized $V_{\text {OC }}$ curves for five solar cells of each investigated samples after 200-h aging test; in particular, the curves are grouped for sample A (curve A) and sample B (curve B).

behavior displayed by the reference sample A. As discussed earlier, the thermal-stress induced $J_{0}$ decreasing trend could be explained by hypothesizing a decrease of the D/A interfacial area. Moreover, the less is the interpenetration between $\mathrm{D}$ and A materials, the higher is the electric fields at the interface by reducing the device's $J_{\mathrm{SC}}$ [45], [46]. Thus, the simultaneous reduction of both $J_{0}$ and $J_{\mathrm{SC}}$ in the case of sample B can be indicative of a less interpenetrated $\mathrm{ZnPc} / \mathrm{C}_{60}$ interface by eventually justifying the increasing $V_{\mathrm{OC}}$ trend during the aging time [Fig. 1(b)]. Finally, in order to exclude $V_{\mathrm{OC}}$ dependence from $E_{\mathrm{CT}}$ as suggested by (1), EL measurements were carried out on the stressed samples [Fig. 2(b)].

First, since the EL peaks spectral position was not affected by the applied stress test, it is possible to conclude that prolonged annealing did not affect the $E_{\mathrm{CT}}$ [47]-[49] at D/A interfaces. Thus, by looking at (1), the increasing $V_{\mathrm{OC}}$ trend for sample B [Fig. 1(b)] can be imputed to an overall increase in the second term $\left[\mathrm{nkT} / \mathrm{q} *\left(\ln \left(J_{\mathrm{SC}}\right) / J_{0}\right)\right]$ that is strongly dependent from the active layer morphology. Furthermore, due to the global nature of the electrical excitation in EL analysis, any thermal-induced degradation of transporting layers, electrodes, and interfaces between them can be excluded, since the thermal-aged samples [Fig. 2(b), curve B] showed an increased EL emission intensity with respect to the reference ones [Fig. 2(b), curve A]. Starting from this assumption, any EL peak intensity change after thermal stress has to be correlated with charges recombination process modification and/or interfaces degradation involving the active layers.

The reported investigation suggests a strong morphological change in the active materials inducing a reduction of D/A interfacial area and subsequently a marked reduction of the inverse saturation current $J_{0}$. With the aim to further support this analysis, $n$ ideality factor has been extracted by the indark $I-V$ characteristics and the trend during the time is 
(a)

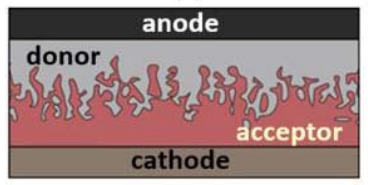

(c)

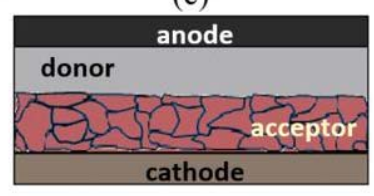

Fig. 3. Schematic of D/A interface in a planar heterojunction. (a) Interpenetrated and (b) smoothed D/A layer interfaces. (c) Coarsening process of $\mathrm{C}_{60}$ acceptor layer in thermal-stressed devices.

reported in Fig. 2(c). The observed $n$ trend is compatible with the progressive reduction of $J_{\mathrm{SC}}$ [Fig. 1(b)] and could be explained with a less interpenetrated $\mathrm{ZnPc} / \mathrm{C}_{60}$ interface and eventually with an increased "grade of order" at D/A interface. Garcia-Belmonte [33] reported the effect of disorder on charge carrier recombination flux in bulk heterojunction solar cell. The author confirmed, by means of theoretical simulations, that the recombination current follows an exponential voltage dependence parameterized by the parameter $\beta$ (inverse of the diode ideality factor $n$ ), which reduces PCE by lowering the device's FF [32] and $V_{\mathrm{OC}}$. Since $\beta$ is directly related to the disorder degree $\sigma$ of the considered layer $\left[\beta=1 / \mathrm{n} \propto \ln \left(\sigma^{-1}\right)\right]$, a change in the degree of order in bulk material can be probed by an evident change in the diode ideality factor $n$ and in a changed FF trend.

Thus, in the case of thermal-stressed sample B, the decrease in $n$ index, as well as the FF increasing trend, can be explained by supposing an increased order at D/A interfaces [33], as schematically represented in Fig. 3.

With the aim to assess the impact of each term of (1) on the device's $V_{\mathrm{OC}}$, all $J_{\mathrm{SC}}, J_{0}$, and $n$ trends previously extracted for the thermal-stressed device were used to calculate the expected $V_{\mathrm{OC}}$ value at each stress stage. The calculated $V_{\mathrm{OC}}$ time trend reported with red star symbols and dashed line in Fig. 1(b) is perfectly matching the measures $V_{\mathrm{OC}}$ values extracted from 1 SUN measurements by further validating our analysis based on the combination between in-dark and 1 SUN $I-V$ measurements.

The $n$ ideality factor time trend previously reported in Fig. 2(c) can provide an interesting starting point in order to discriminate the effect of temperature on both $\mathrm{D}$ and $\mathrm{A}$ layers. In fact, $n$ value extracted under the dark condition is well known to be mainly affected by the higher mobility active layer [50]. Several works focused their attention on mobility in OSC by reporting an electron mobility in pristine $\mathrm{C}_{60}\left(2 \cdot 10^{-1} \mathrm{~cm}^{2} / \mathrm{V} \cdot \mathrm{s}\right)$ about two order of magnitude higher than holes mobility in pristine $\mathrm{ZnPc}\left(1.9 \cdot 10^{-3} \mathrm{~cm}^{2} / \mathrm{V} \cdot \mathrm{s}\right)$. Thus, a strong modification of the acceptor layer morphology could explain the decreasing trend of $n$ ideality factor for devices under prolonged thermal stress.
Furthermore, due to the molecule spherical shape, $\mathrm{C}_{60}$ can arrange more easily in a dense crystalline packing compared to the planar-shaped $\mathrm{ZnPc}$ molecule under particular environmental conditions [51]. For example, during the active layers growing, the crystalline arrangement of $\mathrm{C}_{60}$ molecules after the initial stacking is energetically and sterically favored contrary to what happens to $\mathrm{ZnPc}$ molecules which remain nanocrystalline or amorphous [52].

Thus, $\mathrm{C}_{60}$ molecules aggregation can be assumed as a driving force for phase separation at $\mathrm{ZnPc} / \mathrm{C}_{60}$ interface not only during the layer deposition process but also during applied thermal stress. In fact, thermal aging can induce a partial crystallization/polymerization in the $\mathrm{C}_{60}$ layer that can decrease the initial D/A interfacial area by increasing the size of $\mathrm{C}_{60}$ domain. The increasing of $\mathrm{C}_{60}$ domain dimensions can be demonstrated by investigating the recombination mechanisms within the aged devices.

A first indication about the predominant recombination mechanism within the devices can be provided by the value of the $n$ ideality factor. In fact when $n$ takes values next to 2 , as well as the values extracted for the tested devices [Fig. 2(c)], trap-assisted recombination mechanisms have a major impact onto the device's dynamic with respect to the charge carrier-assisted Langevin recombination that is predominant when $n$ is close to 1 [35].

In particular, Fig. 2(c) showed a temperature-induced reduction of $n$ value starting from 2 until about 1.7 clearly indicating a marked decrease in trap-assisted recombination rate during the applied thermal stress. Recently, Burtone et al. [53] demonstrated the presence of traps states in $\mathrm{ZnPc} / \mathrm{C}_{60}$ solar cells; in particular, trap states at $\mathrm{ZnPc} / \mathrm{C}_{60}$ interfaces have proofed to have an electron-trapping character by strongly affecting the electrons transport in the acceptor layer.

The decreased interfacial trap state density can support the reduction in the trap-assisted recombination in the thermalstressed devices. That is in line with a thermal-induced enlargement of $\mathrm{C}_{60}$ domains that forces a rearrangement at the D/A interface by decreasing the trap states density and by finally positively affecting the electron mobility and lifetime in the stressed device.

In this regard, Schünemann et al. [52] showed that the presence of crystalline $\mathrm{C}_{60}$ domains leads to enhanced charge carrier transport with an increased charges mobility. In order to extract the charge lifetime $\left(\tau_{\text {eff }}\right)$, large perturbation OCVD measurements were performed on the tested samples [54], [55]. $\tau_{\text {eff }}$ versus the normalized $V_{\mathrm{OC}}$ ( $V_{\mathrm{OC}_{-}}$norm) trends are reported in Fig. $2(\mathrm{~d}) ; \tau_{\text {eff }}$ values have been calculated by the following equation [56]:

$$
\tau_{\text {eff }}=-\frac{k_{B} T}{q}\left(\frac{d V_{\mathrm{oc}}}{d t}\right)^{-1}
$$

In particular, OCVD profiles were acquired for five devices on each tested samples in order to improve the results' statistic. Curves are distinguished by a different color for each sample: sample A green curves and sample B blue curves.

Quite notably, $\tau_{\text {eff }}$ values extracted for thermal-stressed devices [Fig. 2(d), curve B] were higher than the reference ones [Fig. 2(d), curve A]. Thus, it is possible to assert that 

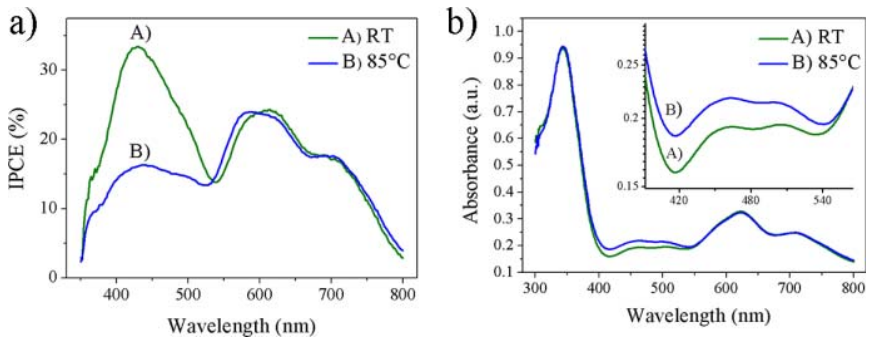

Fig. 4. (a) IPCE and (b) absorption spectra for the investigated samples $A$ (curve $A$ ) and sample $B$ (curve $B$ ) after aging test. Absorbance was acquired on the sample active area between adjacent cells. Inset: spectral region between 400 and $550 \mathrm{~nm}$ in semilogarithmic scale.

the prolonged thermal stress (about $200 \mathrm{~h}$ ) induced an overall increase in the charges lifetime $\tau_{\text {eff }}$ with respect to reference devices stored in GB at RT. More in detail, OCVD measurements can provide information about nongeminate recombination pathways since are strongly related to the dynamic of dissociated charges within the cell. Thus, the overall increased lifetime $\tau_{\text {eff }}$ in the case of thermal-aged devices can be related to an overall decrease in nongeminate recombination within the device that is in line with the decreased trap-assisted recombination rate derived by in-dark $I-V$ measurements. As a further confirmation, Vandewal et al. [41] demonstrated an inverse proportionality between $J_{0}$ and the charges lifetime $\tau_{\text {eff }}$ as well as between $\tau_{\text {eff }}$ and the D/A interfacial area, that is perfectly in line with our investigation.

Thus, a thermal-induced reduction of D/A interfacial area can likely explain the decreased trap state assisted recombination and an increased free charges lifetime.

\section{B. Spectrally Resolved Measurements}

The whole IPCE spectrum was acquired in the middle of the active area for both the investigated samples. The spectra are reported in Fig. 4 as absolute values.

Regarding thermal-stressed device, the IPCE spectrum [Fig. 4(a), curve B] underwent significant losses only in the $\mathrm{C}_{60}$ absorption spectral region (about $-50 \%$ ), while the photo-generated current due to the $\mathrm{ZnPc}$ layer did not undergo evident changes, apart a weak blue shift. This latter has been already observed by Zeng et al. [17] and it was correlated with a morphological change at the D/A interface.

As a matter of fact, the IPCE analysis can provide a complete overview over the physical and electrical processes within the complete device. In particular, (3) [57] details for each factor composing the IPCE, the dependence from the wavelength $\lambda$, the applied voltage $V$ determining the internal electric field $E$, and the temperature $T$

$$
\begin{aligned}
& \operatorname{IPCE}(\alpha, V, T) \\
& \quad=\eta_{\mathrm{PA}}(\lambda) \eta_{\mathrm{ED}}(T) \eta_{\mathrm{CT}}(T) \eta_{\mathrm{CD}}(E, T) \eta_{\mathrm{CP}}(E, T) \eta_{\mathrm{CC}}(E, T) .
\end{aligned}
$$

Each factor is following detailed: $\eta_{\mathrm{PA}}(\lambda)$ is the photon absorption efficiency, $\eta_{\mathrm{ED}}(T)$ is the exciton diffusion efficiency, $\eta_{\mathrm{CT}}$ is the charge transfer efficiency, $\eta_{\mathrm{CD}}(E, T)$ is the dissociation of the electron-hole pair efficiency, $\eta_{\mathrm{CP}}(E, T)$ is the charge transport efficiency, and $\eta_{\mathrm{CC}}(E)$ is the charge collection at the electrodes efficiency.

The expression reported in (3) can be a useful tool in explaining the marked IPCE reduction over the $\mathrm{C}_{60}$ absorption spectral region recorded in the case of the thermal-stressed device. EL measurements reported in Fig. 2(b) showed an increased emission for the thermal-stressed sample by excluding a reduction of charge transport $\left(\eta_{\mathrm{CP}}\right)$ and charge collection $\left(\eta_{\mathrm{CC}}\right)$ efficiencies at the electrodes, even supported by the increasing FF time trend [58] [Fig. 1(c)]. Furthermore, the increased EL emission allows us likely to exclude any degradation involving transporting layers (BCP and $\mathrm{MoO}_{3}$ ) by confirming the thermal degradation affects active $\mathrm{D}$ and/or A layers. At the same time, the absence of an evident EL peak shift rules out a change in the charge transfer efficiency $\left(\eta_{\mathrm{CT}}\right)$.

Moreover, the reduction of trap state at the D/A interface and the overall reduction of geminate recombination previously demonstrated by transient analysis rule out a reduced excitons dissociation efficiency $\left(\eta_{\mathrm{CD}}\right)$ for thermal-stressed samples.

Thus, by combining the information provided by transient analysis with those by IPCE and EL spectra, it is possible to assert that the main effect of thermal stress involves the photon absorption $\left(\eta_{\mathrm{PA}}\right)$ and/or the exciton diffusion $\left(\eta_{\mathrm{ED}}\right)$ efficiencies within the acceptor material.

Fig. 4(b) reports the absorbance acquired on the investigated substrates in the zone between adjacent cells where only the Ag contact is absent. The reported spectra show some prominent absorption bands at $350 \mathrm{~nm}$ and in the range between 550 and $800 \mathrm{~nm}$. While the absorption peaks at 620 and $720 \mathrm{~nm}$ can be inferred to the $\alpha$-phase of $\mathrm{ZnPc}$ donor layer [59], thin film $\mathrm{C}_{60}$ shows characteristic bands at 260 and $350 \mathrm{~nm}$ which are usually observed even in solution [60]. Moreover, in the solid state, the $\mathrm{C}_{60}$ bands shift in wavelength and become broader with respect to those observed in solution. These effects have been assigned either to Coulombic interactions between $\mathrm{C}_{60}$ molecules and/or to structural disorder [61]. In the solid state, the absorption spectrum exhibits a broadband between 400 and $560 \mathrm{~nm}$ which has no straightforward counterpart in solution [62]. This band has been previously attributed to molecular transitions allowed in the film due to the change of symmetry of a system constituted of several $\mathrm{C}_{60}$ molecules upon formation of aggregates [63]. These optical absorption features suggest that $\mathrm{C}_{60}$ domains are formed during the thermal evaporation of the thin acceptor film. Since the broadband between 400 and $560 \mathrm{~nm}$ is unequivocally indicative of aggregated $\mathrm{C}_{60}-\mathrm{C}_{60}$ interactions, it can be used as a probe of enlarged $\mathrm{C}_{60}$ domain even in a complete device.

Note that Fig. 4(b) (inset) shows a remarkable increase in the spectral region between 400 and $540 \mathrm{~nm}$ for thermalstressed sample with respect to the sample A that can be easily explained supposing a thermal stress-induced coarsening process of the $\mathrm{C}_{60}$ domains in the acceptor layer (schematically represented in Fig. 3(c)].

Recently, McAfee et al. [64] reported that ultrathin $\mathrm{C}_{60}$ films on the top of $\mathrm{CuPc}$ are unstable under even relatively low-temperature annealing conditions, resulting in large-scale 
lateral dewetting. The authors observed an average increase in $\mathrm{C}_{60}$ clusters size in both height and width on the CuPc layer after $5 \mathrm{~h}$ of annealing at $105^{\circ} \mathrm{C}$. Since the temperature used in this paper $\left(85^{\circ} \mathrm{C}\right)$ is quite similar and the thermal stress is applied for a prolonged time (over $200 \mathrm{~h}$ ), the increased absorption in the spectral region between 400 and $560 \mathrm{~nm}$ [Fig. 4(b), curve B] can be unequivocally ascribed to an increased intermolecular interaction in the $\mathrm{C}_{60}$ solid film, induced by thermal stress.

Thus, the huge decrease in the IPCE spectra for thermalstressed samples affecting the $\mathrm{C}_{60}$ absorption spectral region [Fig. 4(a), curve B] cannot be related to a loss in photon absorption efficiency $\left(\eta_{\mathrm{PA}}\right)$, since the acceptor layer absorbance is even slightly increased upon thermal aging.

By summarizing the results on thermal-stressed sample, it is possible to assert that the strong decrease in the IPCE over the spectral region of $\mathrm{C}_{60}$ absorption can be related to a decreased exciton diffusion efficiency $\left(\eta_{\mathrm{ED}}\right)$ in the acceptor layer, due to a strong temperature-induced morphological change in the $\mathrm{C}_{60}$ material.

Quite recently, Burlingame et al. [65] reported a similar investigation on planar $\mathrm{SubPc} / \mathrm{C}_{60}$ heterojunction. The authors demonstrated, by means of Fourier transform infrared spectroscopy measurements, that upon illumination in a $\mathrm{N}_{2}$ environmental, $\mathrm{C}_{60}$ undergoes a significant photochemical transformation consisting in an oligomerization process. Due to that, the IPCE spectra recorded during aging time showed a similar behavior to that pointed out in this paper with a strong IPCE decrease affecting the $\mathrm{C}_{60}$ absorption spectral region.

Furthermore, solution-based transient absorption measurements have shown that the exciton lifetime of $\mathrm{C}_{60}$ oligomers $\left(\mathrm{C}_{120}\right.$ and $\left.\mathrm{C}_{180}\right)$ was shorter than that of the monomer [66], [67]. In fact, in the $\mathrm{C}_{60}$ acceptor layer, a portion of nonradiative exciton decay events results in the formation of oligomers; in particular, in the case of $\mathrm{C}_{60}$, the exciton energy is sufficient to drive [2+2] cycloaddition between the carbon double bonds of adjacent $\mathrm{C}_{60}$ molecules to form oligomeric by-products [68]. As a result, the molecular symmetry responsible for the dark singlet state of $\mathrm{C}_{60}$ is reduced, which shortens the exciton lifetime in the oligomers. Here, the observed IPCE and $J_{\mathrm{SC}}$ decrease in thermal-stressed samples can be likely explained by the reduced charge diffusion length negatively affecting the exciton lifetime.

Finally, the PCE burn-in phenomenon usually observed for encapsulated devices during early thermal aging can be clearly explained by the progressive coarsening of $\mathrm{C}_{60}$ molecules when it is employed as an acceptor layer in planar heterojunction solar cells.

\section{Raman Analysis}

As further confirmation, Raman analysis has been performed on the stressed samples. The analysis of Raman spectra acquired by focusing the laser beam on the D/A interface of the investigated device can provide an experimental evidence of the structural change occurred in donor and/or acceptor material. The spectrum of $100 \mathrm{~nm} \mathrm{ZnPc: \textrm {C } _ { 6 0 }}$ coevaporated layer (1:1 by weight) on the glass is reported in Fig. 5(a);
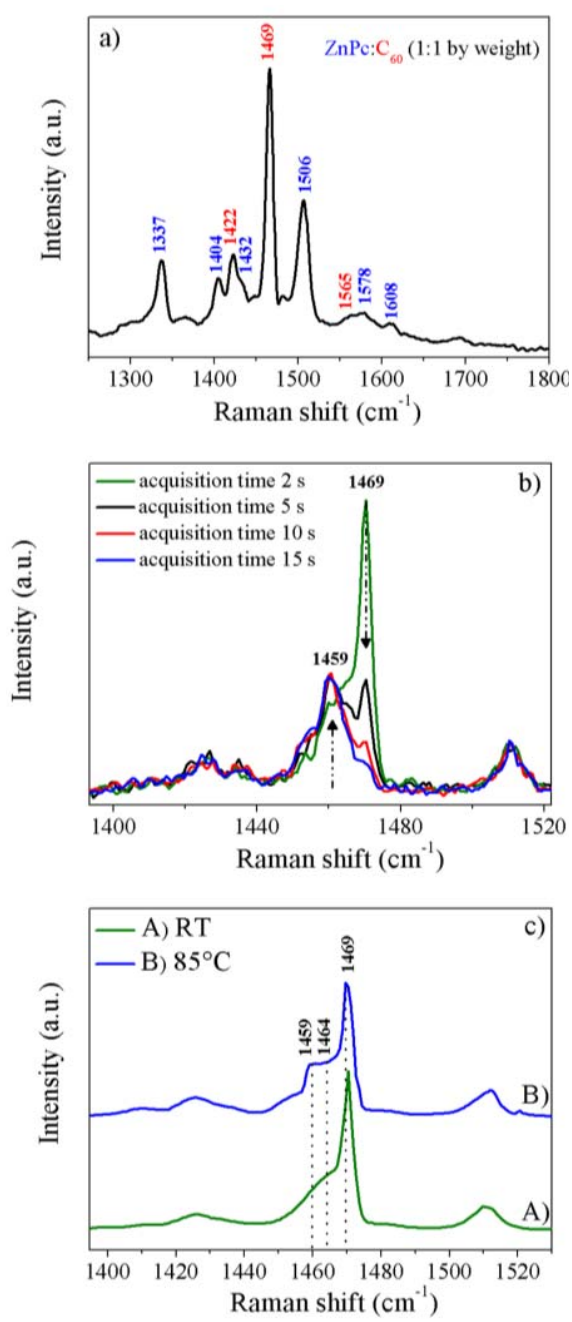

Fig. 5. (a) Raman spectrum acquired by focusing the 514.5-nm laser beam radiation on a $\mathrm{ZnPc}$ : $\mathrm{C}_{60}$ (1:1 by weight) coevaporated layer. (b) Raman spectra acquired on the device's active area for sample A by progressively varying the acquisition time and the acquisition point. (c) Raman spectra acquired by focusing the $514.5-\mathrm{nm}$ laser beam at the D/A interface of one device for each investigated samples (sample $A$ curve $A$, sample $B$ curve $B$, and sample $C$ curve $C$ ). The laser intensity on the samples surfaces was about $0.026 \mathrm{~mW} / \mu \mathrm{m}^{2}$, the acquisition time was $2 \mathrm{~s}$. The entire spectrum was collected in $2 \mathrm{~s}$ over wavelength scan range between 1250 and $1800 \mathrm{~cm}^{-1}$.

the sample was sealed in an inert condition immediately after the evaporation.

The choice to acquire the Raman spectrum on the $\mathrm{ZnPc}: \mathrm{C}_{60}$ (1:1) coevaporated layer has the aim to avoid any laser-induced polymerization phenomena between neighboring $\mathrm{C}_{60}$ molecules, in order to exactly identify the characteristic vibration of $\mathrm{C}_{60}$ monomeric form.

Among the reported vibrational bands, $\mathrm{ZnPc}$ showed $\mathrm{A}_{1 \mathrm{~g}}$ modes at 1337 and $1404 \mathrm{~cm}^{-1}, \mathrm{~B}_{1 \mathrm{~g}}$ at 1506 and $1578 \mathrm{~cm}^{-1}$, $B_{2 g}$ modes at 1432 and $1608 \mathrm{~cm}^{-1}$ [69]. On the other hand, $\mathrm{C}_{60}$ Raman spectrum is characterized by the strong line at $1469 \mathrm{~cm}^{-1}$, ascribed to the pentagonal-pinch $A_{\mathrm{g}}$ mode [70]. The remaining weak bands at 1422 and $1565 \mathrm{~cm}^{-1}$ are commonly ascribed to the $\mathrm{H}_{\mathrm{g}}$ modes [71]. Splitting of the modes may be attributed to the loss of symmetry of the $\mathrm{C}_{60}$ 
molecule owing to interactions with its neighbors in the solid state. Moreover, it was found that the Raman lines and particularly the pinch mode at $1469 \mathrm{~cm}^{-1}$ for the pristine $\mathrm{C}_{60}$ are very much affected by photopolymerization [70]. Moreover, oxygen that was considered for a long time responsible of Raman shift of pentagonal pinch mode [72] is now known to not induce measurable change on Raman spectrum relative to that observed in the oxygen-free solid $\mathrm{C}_{60}$ [73]. Raman spectra reported in literature related to laser irradiated $\mathrm{C}_{60}$ layers have shown the existence of $\mathrm{C}_{120}, \mathrm{C}_{180}$, and higher oligomers in the spectral region between 120 and $1600 \mathrm{~cm}^{-1}$. In particular, in photopolymerized solid $\mathrm{C}_{60}$, the Raman peak at $1464 \mathrm{~cm}^{-1}$ has been observed and assigned to the dimer mode, while the bands at 1452 and $1459 \mathrm{~cm}^{-1}$ have been assigned to the polymer mode including trimer and higher oligomer modes [70].

Sakai et al. [70] investigated the photopolymerization process of the evaporated $\mathrm{C}_{60}$ layer by means of Raman scattering by taking into account the two opposite phenomena of photocreation and thermal decomposition of monomer, dimer, and higher polymers. The authors reported that when the effect of light photopolymerizazion is predominant on the local thermal annealing induced by Raman light source (low sample temperature), the formation of trimer and dimer decrease the initial monomer density in a typical Raman spectrum of pristine $\mathrm{C}_{60}$ (obtained by irradiating the sample just for $10 \mathrm{~s}$ and employing a laser power density of about $140 \mathrm{~mW} / \mathrm{mm}^{2}$ ).

On the contrary, by prolonging laser irradiation in time and by increasing the sample temperature, a local increased temperature $T_{\text {spot }}>400 \mathrm{~K}$ is achieved and the decomposition of previously formed higher polymers is favored.

More in detail, Burger et al. [74] reported a careful study on the photopolymerization process induced by laser radiation on $\mathrm{C}_{60}$ layer. The author found that the higher is the temperature of the sample during the photopolymerization progress; the lower is the possibility to induce photopolymerized $\mathrm{C}_{60}$. This phenomenon is mainly due to the higher kinetic energy of the $\mathrm{C}_{60}$ molecules and the larger lattice constant. Since the Raman spectra acquired in this paper have carried out by employing a visible excitation source at $514.5 \mathrm{~nm}$ with a power density $\left(0.026 \mathrm{~mW} / \mu \mathrm{m}^{2}\right)$ comparable to that used by Burger (measured on the sample by means of a bolometer sensible to visible radiation), we can confidently conclude that the Raman measurement induces photopolymerization on the investigated layer. Furthermore, since the acquisition time for one single Raman spectrum is quite short $(2 \mathrm{~s}$ per spectrum) the photopolymerization phenomenon is just at the beginning state and is evident only for the sample in which the intermolecular interactions between neighboring carbon atoms on adjacent $\mathrm{C}_{60}$ molecules are favored.

To demonstrate the effect of the photopolymerization process on a fresh and encapsulated device, several acquisitions of device's active layers Raman spectra are reported in Fig. 5(b) by varying the acquisition time. As it is possible to note, the photopolymerization has a huge impact on $\mathrm{C}_{60}$ pentagonal pinch mode. The band related to monomeric form at $1469 \mathrm{~cm}^{-1}$ hugely decreased until to disappear quite
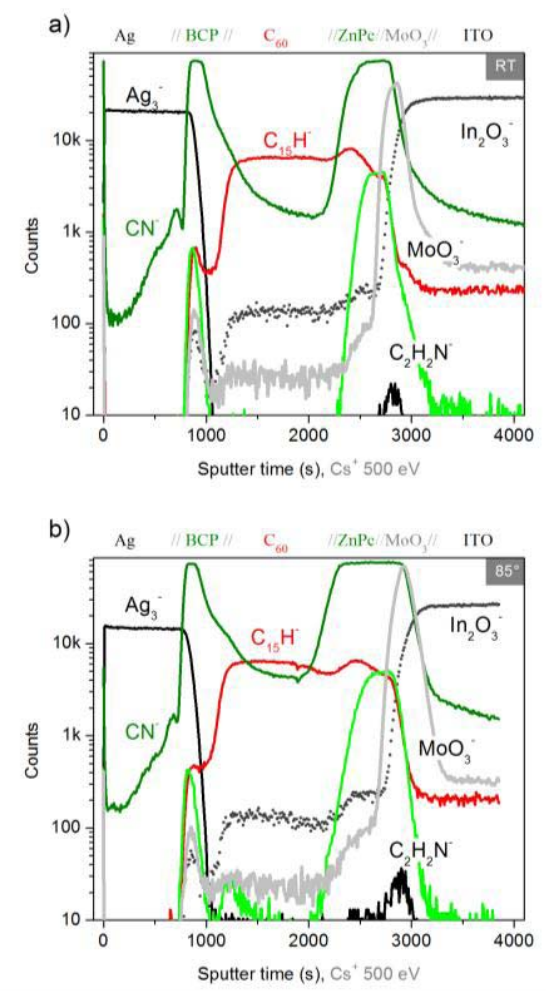

Fig. 6. (a) ToF-SIMS profiles obtained on the RT. (b) $85^{\circ} \mathrm{C}$ annealed solar cells.

completely while the progressive rise of a $1459 \mathrm{~cm}^{-1}$ peak ascribable to the polymeric form was progressively detected.

Raman spectra acquired by focusing the laser beam on the D/A interface of the device active area are reported in Fig. 5(c) for the investigated samples A (curve A) and B (curve B). The spectra were acquired by exposing the sample to the laser radiation for $2 \mathrm{~s}$ and by using 1800 lines/mm grating.

It is noteworthy that the different aging conditions have a huge impact on the shape of the central peak at $1469 \mathrm{~cm}^{-1}$, ascribed at the pentagonal pinch mode of $\mathrm{C}_{60}$ in its monomeric form. In fact, while in the device A [curve A, Fig. 5(c)] the $1469 \mathrm{~cm}^{-1}$ Raman band was predominant and only a broader shoulder around $1464 \mathrm{~cm}^{-1}$ was revealed, ascribed to a residual density of $\mathrm{C}_{60}$ in its dimeric form, in thermal-stressed device [spectrum B, Fig. 5(c)] a well evident Raman band at $1461 \mathrm{~cm}^{-1}$ appeared. As previously detailed, the appearance of this vibrational band is a clear indication of an increased amount of polymerized form of $\mathrm{C}_{60}$. Due to the shorter irradiation time, the polymerization process in all the investigated samples is not completed and the Raman band of monomeric $\mathrm{C}_{60}$ at $1469 \mathrm{~cm}^{-1}$ was still predominant in all the acquired spectra. The higher polymerization process efficiency in the thermal-stressed sample, evident in the appearance of a wellresolved band at $1459 \mathrm{~cm}^{-1}$, is well compatible with an increased dimension of $\mathrm{C}_{60}$ domains induced by temperature. In fact, the increased interaction between neighboring $\mathrm{C}_{60}$ molecule induced by the thermal aging process, gives rise to the formation of polycrystalline domains that easier polymerized once irradiated by the laser source. 
Thus, it is possible to conclude that a more efficient laserinduced photopolymerization process at RT in the case of thermal-stressed sample can be related to an increased interaction between $\mathrm{C}_{60}$ molecules in their monomeric phase.

\section{ToF-SIMS Analysis}

To further investigate the aging effects on layers and interfaces, the pristine and aged cells are depth profiled with ToF-SIMS using low energy $(500 \mathrm{eV}) \mathrm{Cs}^{+}$sputtering beam which is particularly suited to profile such hybrid stacks [30], [75].

The depth profiles in Fig. 6 show very sharp interfaces and very similar characteristic molecular signals from the different layers. However, in the annealed cell [Fig. 6(b)], a considerably stronger persistence of the $\mathrm{CN}^{-}$signal is found in the $\mathrm{C}_{60}$ layer (at $\sim 2000 \mathrm{~s}$ ) indicating the presence of a less compact $\mathrm{C}_{60}$ layer or suggesting that, because of the presence of grains in the $\mathrm{C}_{60}$ layer, $\mathrm{CN}^{-}$ions could be extracted from the underlying $\mathrm{ZnPc}$ layer.

\section{CONCLUSiON}

In this paper, the stability of glass-glass encapsulated small molecule solar cells with the following device's structure $\mathrm{ITO} / \mathrm{MoO}_{3} / \mathrm{ZnPc} / \mathrm{C}_{60} / \mathrm{BCP} / \mathrm{Ag}$ has been investigated under prolonged thermal stress $\left(85^{\circ} \mathrm{C}\right)$. In particular, temperature-induced degradation processes suffered by the $\mathrm{D} / \mathrm{A}$ active layers and by the relative interfaces in the planar structure were pointed out by a combination of numerous electrical and spectroscopic characterization techniques. Such deep investigation allowed for the first time in the literature to explain the observed burn-in phenomenon that is responsible for a reduction of the device's performance during the first hours of the prolonged thermal stress test. In particular, the marked reduction in the short-circuit current $(-25 \%)$ during aging time has been finally unequivocally ascribed to an increased dimension of $\mathrm{C}_{60}$ domains and consequently decreased excitons lifetime. As matter of fact, the investigation carried out in this paper provided a deeper comprehension of the degradation mechanisms that should be taken into account in designing more stable organic active materials and more robust sealing techniques robust under the real atmospheric working conditions. The improved long-term stability achieved by preventing the degradation mechanisms could be a crucial step forward in order to make reliable and durable organic PV toward the market production.

\section{ACKNOWLEDGMENT}

The authors would like to thank Dr. E. Voroshazi and Dr. A. Hadipour for useful discussions and scientific support.

\section{REFERENCES}

[1] O. A. Abdulrazzaq, V. Saini, S. Bourdo, E. Dervishi, and A. S. Biris, "Organic solar cells: A review of materials, limitations, and possibilities for improvement," Particulate Sci. Technol., vol. 31, no. 5, pp. 427-442, 2013.

[2] M. C. Scharber and N. S. Sariciftci, "Efficiency of bulk-heterojunction organic solar cells," Prog. Polym. Sci., vol. 38, no. 12, pp. 1929-1940, 2013.
[3] Q. Huang and H. Li, "Recent progress of bulk heterojunction solar cells based on small-molecular donors," Chin. Sci. Bull., vol. 58, no. 22, pp. 2677-2685, 2013 .

[4] Q. Zhang et al., "Small-molecule solar cells with efficiency over 9\%," Nature Photon., vol. 9, no. 1, pp. 35-41, 2014.

[5] B. Kan et al., "A series of simple oligomer-like small molecules based on oligothiophenes for solution-processed solar cells with high efficiency," J. Amer. Chem. Soc., vol. 137, no. 11, pp. 3886-3893, 2015.

[6] A. Mishra and P. Bäuerle, "Small molecule organic semiconductors on the move: Promises for future solar energy technology," Angew. Chem. Int. Ed., vol. 51, no. 9, pp. 2020-2067, Aug. 2012.

[7] L. Meng et al., "Organic and solution-processed tandem solar cells with 17.3\% efficiency," Science, vol. 361, no. 6402, pp. 1094-1098, 2018.

[8] M. O. Reese et al., "Consensus stability testing protocols for organic photovoltaic materials and devices," Solar Energy Mater. Solar Cells, vol. 95, no. 5, pp. 1253-1267, 2011.

[9] H. Cao et al., "Recent progress in degradation and stabilization of organic solar cells," J. Power Sources, vol. 264, pp. 168-183, Oct. 2014.

[10] E. Voroshazi, B. Verreet, A. Buri, R. Müller, D. Di Nuzzo, and P. Heremans, "Influence of cathode oxidation via the hole extraction layer in polymer: Fullerene solar cells," Organic Electron., vol. 12, no. 5, pp. 736-744, 2011.

[11] M. Hermenau, M. Riede, K. Leo, S. A. Gevorgyan, F. C. Krebs, and K. Norrman, "Water and oxygen induced degradation of small molecule organic solar cells," Solar Energy Mater. Sol. Cells, vol. 95, no. 5, pp. 1268-1277, 2011.

[12] Y. Sun et al., "Efficient, air-stable bulk heterojunction polymer solar cells using $\mathrm{MoO}_{\mathrm{x}}$ as the anode interfacial layer," Adv. Mater., vol. 23, no. 19, pp. 2226-2230, 2011.

[13] D. Chalal, R. Garuz, D. Benachour, J. Bouclé, and B. Ratier, "Influence of an electrode self-protective architecture on the stability of inverted polymer solar cells based on P3HT:PCBM with an active area of $2 \mathrm{~cm}^{2}$," Synth. Met., vol. 212, pp. 161-166, Feb. 2016.

[14] H. Cao and K. Ishikawa, "Lateral oxygen diffusion dominated extrinsic degradation of small molecular organic solar cells," Sol. Energy Mater. Solar Cells, vol. 109, pp. 215-219, Feb. 2013.

[15] R. Lessmann, Z. Hong, S. Scholz, B. Maennig, M. K. Riede, and K. Leo, "Aging of flat heterojunction zinc phthalocyanine/fullerene $\mathrm{C}_{60}$ organic solar cells," Organic Electron., vol. 11, no. 4, pp. 539-543, 2010.

[16] M. Tavakkoli, R. Ajeian, M. N. Badrabadi, S. S. Ardestani, S. M. H. Feiz, and K. E. Nasab, "Progress in stability of organic solar cells exposed to air," Solar Energy Mater. Sol. Cells, vol. 95, no. 7, pp. 1964-1969, 2011.

[17] W. Zeng, K. S. Yong, Z. M. Kam, F. Zhu, and Y. Li, "Effect of blend layer morphology on performance of $\mathrm{ZnPc}_{\mathrm{C}} \mathrm{C}_{60}$-based photovoltaic cells," Appl. Phys. Lett., vol. 97, no. 13, p. 133304, 2010.

[18] S. Pfuetzner, J. Meiss, A. Petrich, M. Riede, and K. Leo, "Improved bulk heterojunction organic solar cells employing $\mathrm{C}_{70}$ fullerenes," Appl. Phys. Lett., vol. 94, no. 22, p. 223307, 2009.

[19] V. Kažukauskas, A. Arlauskas, M. Pranaitis, R. Lessmann, M. Riede, and $\mathrm{K}$. Leo, "Conductivity, charge carrier mobility and ageing of $\mathrm{ZnPc} / \mathrm{C}_{60}$ solar cells," Opt. Mater., vol. 32, no. 12, pp. 1676-1680, 2010.

[20] A. Agresti et al., "Efficiency and stability enhancement in perovskite solar cells by inserting lithium-neutralized graphene oxide as electron transporting layer," Adv. Funct. Mater., vol. 26, no. 16, pp. 2686-2694, 2016.

[21] A. Agresti et al., "Graphene-perovskite solar cells exceed $18 \%$ efficiency: A stability study," ChemSusChem, vol. 9, no. 18, pp. 2609-2619, 2016.

[22] A. Agresti et al., "Graphene interface engineering for perovskite solar modules: $12.6 \%$ Power conversion efficiency over $50 \mathrm{~cm}^{2}$ active area," ACS Energy Lett., vol. 2, no. 1, pp. 279-287, 2017.

[23] A. Agresti, L. Cinà , S. Pescetelli, B. Taheri, and A. Di Carlo, "Stability of dye-sensitized solar cell under reverse bias condition: Resonance Raman spectroscopy combined with spectrally resolved analysis by transmittance and efficiency mapping," Vibrational Spectrosc., vol. 84, pp. 106-117, May 2016.

[24] S. K. Yadav, S. Ravishankar, S. Pescetelli, A. Agresti, F. Fabregat-Santiago, and A. Di Carlo, "Stability of dye-sensitized solar cells under extended thermal stress," Phys. Chem. Chem. Phys., vol. 19, no. 33, pp. 22546-22554, 2017.

[25] A. L. Palma et al., "Mesoscopic perovskite light-emitting diodes," ACS Appl. Mater. Interfaces, vol. 8, no. 40, pp. 26989-26997, 2016.

[26] A. Agresti et al., "Micro-Raman analysis of reverse bias stressed dyesensitized solar cells," RSC Adv., vol. 4, no. 24, pp. 12366-12375, 2014. 
[27] A. Agresti, S. Pescetelli, E. Gatto, M. Venanzi, and A. Di Carlo, "Polyiodides formation in solvent based Dye Sensitized Solar Cells under reverse bias stress," J. Power Sources, vol. 287, pp. 87-95, Aug. 2015.

[28] A. Agresti, S. Pescetelli, S. Casaluci, A. Di Carlo, R. Lettieri, and M. Venanzi, "High efficient perovskite solar cells by employing zincphthalocyanine as hole transporting layer," in Proc. IEEE 15th Int. Conf. Nanotechnol., Jul. 2015, pp. 732-735.

[29] V. A. Tran et al., "Application of nitrogen-doped $\mathrm{TiO}_{2}$ nano-tubes in dye-sensitized solar cells," Appl. Surf. Sci., vol. 399, pp. 515-522, Mar. 2017.

[30] Y. Busby et al., "Aging effects in interface-engineered perovskite solar cells with 2D nanomaterials: A depth profile analysis," Mater. Today Energy, vol. 9, pp. 1-10, Sep. 2018.

[31] J. Bisquert and G. Garcia-Belmonte, "On voltage, photovoltage, and photocurrent in bulk heterojunction organic solar cells," J. Phys. Chem. Lett., vol. 2, no. 15, pp. 1950-1964, 2011.

[32] B. Qi and J. Wang, "Fill factor in organic solar cells," Phys. Chem. Chem. Phys, vol. 15, no. 23, pp. 8972-8982, 2013.

[33] G. Garcia-Belmonte, "Carrier recombination flux in bulk heterojunction polymer: Fullerene solar cells: Effect of energy disorder on ideality factor," Solid. State. Electron., vol. 79, pp. 201-205, Jan. 2013.

[34] R. A. Street, S. Cowan, and A. J. Heeger, "Experimental test for geminate recombination applied to organic solar cells," Phys. Rev. B, Covering Condens. Matter Mater. Phys., vol. 82, no. 12, p. 121301, 2010.

[35] G. Lakhwani, A. Rao, and R. H. Friend, "Bimolecular recombination in organic photovoltaics," Апnи. Rev. Phys. Chem., vol. 65, pp. 557-581, Apr. 2014.

[36] B. Philippa et al., "The impact of hot charge carrier mobility on photocurrent losses in polymer-based solar cells," Sci. Rep., vol. 4, Jul. 2014, Art. no. 5695.

[37] J. Xue, B. P. Rand, S. Uchida, and S. R. Forrest, "A hybrid planar-mixed molecular heterojunction photovoltaic cell," Adv. Mater., vol. 17, no. 1, pp. 66-71, 2005.

[38] P.-H. Huang, C.-J. Huang, K.-L. Chen, J.-C. Ke, Y.-H. Wang, and C.-C. Kang, "Improved reliability of small molecule organic solar cells by double anode buffer layers," J. Nanomaterials, vol. 2014, Jul. 2014, Art. no. 741761

[39] D. Credgington, F. C. Jamieson, B. Walker, T. Q. Nguyen, and J. R. Durrant, "Quantification of geminate and non-geminate recombination losses within a solution-processed small-molecule bulk heterojunction solar cell," Adv. Mater, vol. 24, no. 16, pp. 2135-2141, 2012.

[40] W.-Y. Chou et al., "The importance of $\mathrm{p}-\mathrm{n}$ junction interfaces for efficient small molecule-based organic solar cells," Phys. Chem. Chem. Phys., vol. 14, no. 15, pp. 5284-5288, 2012

[41] K. Vandewal et al., "Increased open-circuit voltage of organic solar cells by reduced donor-acceptor interface area," Adv. Mater., vol. 26, no. 23, pp. 3839-3843, 2014.

[42] A. Maurano et al., "Recombination dynamics as a key determinant of open circuit voltage in organic bulk heterojunction solar cells: A comparison of four different donor polymers," Adv. Mater, vol. 22, no. 44, pp. 4987-4992, 2010.

[43] K. Vandewal, K. Tvingstedt, A. Gadisa, O. Inganäs, and J. V. Manca, "Relating the open-circuit voltage to interface molecular properties of donor: Acceptor bulk heterojunction solar cells," Phys. Rev. B, Covering Condens. Matter Mater. Phys., vol. 81, no. 12, p. 125204, 2010.

[44] M. D. Perez, C. Borek, S. R. Forrest, and M. E. Thompson, "Molecular and morphological influences on the open circuit voltages of organic photovoltaic devices," J. Amer. Chem. Soc., vol. 131, no. 26, pp. 9281-9286, 2009

[45] S. Bertho et al., "Improved thermal stability of bulk heterojunctions based on side-chain functionalized poly(3-alkylthiophene) copolymers and PCBM," Solar Energy Mater. Solar Cells, vol. 110, pp. 69-76, Mar. 2013.

[46] A. Tada, Y. Geng, Q. Wei, K. Hashimoto, and K. Tajima, "Tailoring organic heterojunction interfaces in bilayer polymer photovoltaic devices," Nature Mater., vol. 10, no. 6, pp. 450-455, 2011.

[47] S. Verlaak et al., "Electronic structure and geminate pair energetics at organic-organic interfaces: The case of pentacene/ $\mathrm{C}_{60}$ heterojunctions," Adv. Funct. Mater, vol. 19, no. 23, pp. 3809-3814, 2009.

[48] S. J. Kang et al., "Energy level diagrams of $\mathrm{C}_{60} /$ pentacene/Au and pentacene/C 60 /Au," Synth. Met., vol. 156, no. 1, pp. 32-37, 2006.

[49] A. Ray, D. Goswami, S. Chattopadhyay, and S. Bhattacharya, "Photophysical and theoretical investigations on fullerene/phthalocyanine supramolecular complexes," J. Phys. Chem. A, vol. 112, no. 46, pp. $11627-11640,2008$.
[50] A. H. W. Gert-Jan and P. W. M. Blom, "Diffusion-driven currents in organic-semiconductor diodes," NPG Asia Mater., vol. 6, no. 7, p. e110, 2014.

[51] P. Simon, B. Maennig, and H. Lichte, "Conventional electron microscopy and electron holography of organic solar cells," Adv. Funct. Mater, vol. 14, no. 7, pp. 669-676, 2004.

[52] C. Schünemann et al., "Phase separation analysis of bulk heterojunctions in small-molecule organic solar cells using zinc-phthalocyanine and $\mathrm{C}_{60}$," Phys. Rev. B, Covering Condens. Matter Mater. Phys., vol. 85, no. 24 , p. 245314, 2012.

[53] L. Burtone, J. Fischer, K. Leo, and M. Riede, "Trap states in ZnPc:C60 small-molecule organic solar cells," Phys. Rev. B, Covering Condens. Matter Mater. Phys., vol. 87, no. 4, p. 045432, 2013.

[54] F. Biccari et al., "Graphene-based electron transport layers in perovskite solar cells: A step-up for an efficient carrier collection," Adv. Energy Mater, vol. 7, no. 22, p. 1701349, 2017.

[55] A. Agresti et al., "Graphene and related 2D materials for high efficient and stable perovskite solar cells," in Proc. IEEE 17th Int. Conf. Nanotechnol., Jul. 2017, pp. 145-150.

[56] P. R. F. Barnes et al., "Regan, "Interpretation of optoelectronic transient and charge extraction measurements in dye-sensitized solar cells," Adv. Mater, vol. 25, no. 13, pp. 1881-1922, 2013.

[57] P. Peumans, A. Yakimov, and S. R. Forrest, "Small molecular weight organic thin-film photodetectors and solar cells," J. Appl. Phys., vol. 93, no. 7, pp. 3693-3723, 2003.

[58] N. C. Giebink, B. E. Lassiter, G. P. Wiederrecht, M. R. Wasielewski, and S. R. Forrest, "Ideal diode equation for organic heterojunctions. II. The role of polaron pair recombination," Phys. Rev. B, Covering Condens. Matter Mater. Phys., vol. 82, no. 15, p. 155306, 2010.

[59] S. Senthilarasu, Y. B. Hahn, and S.-H. Lee, "Nano structure formation in vacuum evaporated zinc phthalocyanine ( $\mathrm{ZnPc}$ ) thin films," J. Mater. Sci., Mater. Electron., vol. 19, no. 5, pp. 482-486, 2008.

[60] S. Deguchi, R. G. Alargova, and K. Tsujii, "Stable dispersions of fullerenes, $\mathrm{C}_{60}$ and $\mathrm{C}_{70}$, in water. Preparation and characterization," Langmuir, vol. 17, no. 19, pp. 6013-6017, 2001.

[61] V. Capozzi et al., "Optical spectra and photoluminescence of $\mathrm{C}_{60}$ thin films," Solid State Commun., vol. 98, no. 9, pp. 853-858, 1996.

[62] M. C. Fravventura, J. Hwang, J. W. A. Suijkerbuijk, P. Erk, L. D. A. Siebbeles, and T. J. Savenije, "Determination of singlet exciton diffusion length in thin evaporated $\mathrm{C}_{60}$ films for photovoltaics," J. Phys. Chem. Lett., vol. 3, no. 17, pp. 2367-2373, 2012.

[63] J. Lee, M. Cho, J. D. Fortner, J. B. Hughes, and J.-H. Kim, "Transformation of aggregated $\mathrm{C}_{60}$ in the aqueous phase by UV irradiation," Environ. Sci. Technol., vol. 43, no. 13, pp. 4878-4883, 2009.

[64] T. McAfee, E. Gann, H. W. Ade, and D. B. Dougherty, "Thermallyinduced dewetting in ultra-thin $\mathrm{C}_{60}$ films on copper phthalocyanine," J. Phys. Chem. C, vol. 117, no. 49, pp. 26007-26012, 2013.

[65] Q. Burlingame, X. Tong, J. Hankett, M. Slootsky, Z. Chen, and S. R. Forrest, "Photochemical origins of burn-in degradation in small molecular weight organic photovoltaic cells," Energy Environ. Sci., vol. 8, no. 3, pp. 1005-1010, 2015.

[66] M. Fujitsuka, C. Luo, O. Ito, Y. Murata, and K. Komatsu, "Triplet properties and photoinduced electron-transfer reactions of $\mathrm{C}_{120}$, the [2+2] dimer of fullerene $\mathrm{C}_{60}$, , J. Phys. Chem. A, vol. 103, no. 36, pp. 7155-7160, 1999.

[67] S. M. Bachilo, A. F. Benedetto, and R. B. Weisman, "Triplet state dissociation of $\mathrm{C}_{120}$, the dimer of $\mathrm{C}_{60}$, , J. Phys. Chem. A, vol. 105, no. 43, pp. 9845-9850, 2001.

[68] P. C. Eklund, A. M. Rao, P. Zhou, Y. Wang, and J. M. Holden, "Photochemical transformation of $\mathrm{C}_{60}$ and $\mathrm{C}_{70}$ films," Thin Solid Films, vol. 257, no. 2, pp. 185-203, 1995.

[69] C. Murray et al., "Visible luminescence spectroscopy of free-base and zinc phthalocyanines isolated in cryogenic matrices," Phys. Chem. Chem. Phys., vol. 13, no. 39, pp. 17543-17554, 2011.

[70] M. Sakai, M. Ichida, and A. Nakamura, "Raman scattering study of photopolymerization kinetics in $\mathrm{C}_{60}$ crystals," Chem. Phys. Lett., vol. 335 , nos. 5-6, pp. 559-566, 2001.

[71] S. J. Duclos, R. C. Haddon, S. Glarum, and A. F. Hebard, "Raman studies of alkali-metal doped $\mathrm{A}_{\mathrm{x}} \mathrm{C}_{60}$ films $(\mathrm{A}=\mathrm{Na}, \mathrm{K}, \mathrm{Rb}$, and $\mathrm{Cs} ; \mathrm{x}$ $=0,3$, and 6)," Science, vol. 254, pp. 1625-1627, Dec. 1991.

[72] T. Pichler, M. Matus, J. Kürti, and H. Kuzmany, "Phase separation in KxC60 $(0<=\mathrm{x}<=6)$ as obtained from in situ Raman spectroscopy.," Phys. Rev. B, Condens. Matter, vol. 45, no. 23, pp. 13841-13844, 1992. 
[73] V. G. Hadjiev, P. M. Rafailov, H. Jantoljak, C. Thomsen, and M. K. Kelly, "Influence of the crystal field on the Raman intensity of $\mathrm{C}_{60}$ fullerites," Phys. Rev. B, Condens. Matter, vol. 56, no. 5, pp. 2495-2500, 1997.

[74] B. Burger, J. Winter, and H. Kuzmany, "Dimer and cluster formation in $\mathrm{C}_{60}$ photoreaction," Zeitschrift Physik B Condens. Matter, vol. 101, no. 2, pp. 227-233, 1996.

[75] A. L. Palma et al., "Hybrid perovskite as substituent of indium and gallium in light emitting diodes," Phys. Status Solidi, vol. 13, nos. 10-12, pp. 958-961, 2016.

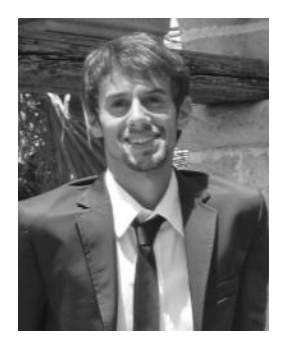

Antonio Agresti is a Researcher at the Electronic Engineering Department, University of Rome Tor Vergata, Rome, Italy. His research activity focuses on organic and hybrid photovoltaics and in particular dye sensitized, organic and perovskite solar cells, and large area module. $\mathrm{He}$ is currently involved in the Graphene Flagship project (Horizon 2020). He has been co-authoring more than 25 papers, besides a number of other publications and several invited talks.

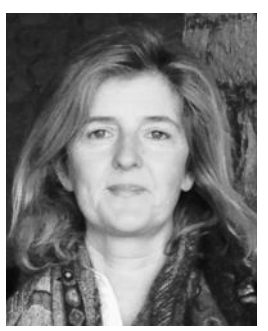

Sara Pescetelli received the master's degree in physics from the University of Rome Tor Vergata, Rome, Italy, in 1995.

She is currently a Physics Technician with the Electronic Engineering Department, University of Rome Tor Vergata. Her current research interests include organic and hybrid photovoltaic devices, especially perovskite-based solar cells and large area modules, dye-sensitized solar cells, and small molecule devices.

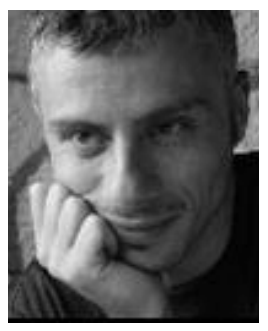

Yan Busby received the M.D. degree in physics from the Sapienza University of Rome, Rome, Italy, in 2006, and the Ph.D. degree in physics from Rome Tre University, Rome, in 2011.

Since 2011, he has been a Post-Doctoral Researcher in physical chemistry of applied materials with the University of Namur, Namur, Belgium. Since 2015, he has been involved in organic/hybrid solar cells, (O)LEDs, and nanomaterials for energy (fuel cells) and catalysis.

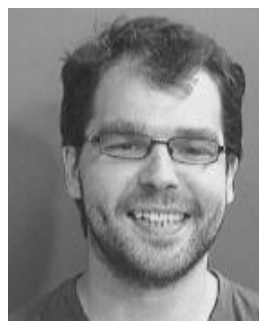

Tom Aernouts is currently a Research and Development Manager of the Thin-Film Photovoltaics (PVs) Group, imec, Leuven, Belgium, where he was involved in thin-film processing and characterization, photovoltaics, and organic electronics. Currently, this group focusses its activities around two main thinfilm PV technologies: inorganic copper indium gallium selenide/sulfide, and the emerging hybrid metal-organic perovskite-based cells. He is also a Program Manager of Solliance Eindhoven, The Netherlands. 